Erratum

\title{
Erratum: Su, T.Y., et al. Effects of Heavy Metal Exposure on Shipyard Welders: A Cautionary Note for 8-Hydroxy-2'-Deoxyguanosine. Int. J. Environ. Res. Public Health 2019, 16, 4813
}

\author{
Ting-Yao Su ${ }^{1,2} \mathbb{D}$, Chih-Hong Pan ${ }^{2,3}$, Yuan-Ting Hsu ${ }^{1,4}$ and Ching-Huang Lai $1,3, * \mathbb{D}$ \\ 1 Graduate Institute of Life Sciences, National Defense Medical Center, Taipei 114, Taiwan; \\ timothy80329@gmail.com (T.-Y.S.); misara116@gmail.com (Y.-T.H.) \\ 2 Institute of Labor, Occupational Safety and Health, Ministry of Labor, New Taipei City 221, Taiwan; \\ chpan@mail.ilosh.gov.tw \\ 3 School of Public Health, National Defense Medical Center, Taipei 114, Taiwan \\ 4 National Institute of Environmental Health Sciences, National Health Research Institutes, Miaoli 350, Taiwan \\ * Correspondence: clai4330@gmail.com
}

check for

updates

Citation: Su, T.-Y.; Pan, C.-H.; Hsu, Y.-T.; Lai, C.-H. Erratum: Su, T.Y., et al. Effects of Heavy Metal Exposure on Shipyard Welders: A Cautionary Note for 8-Hydroxy-

2'-Deoxyguanosine. Int. J. Environ. Res. Public Health 2019, 16, 4813. Int. J. Environ. Res. Public Health 2021, 18 , 3557. https://doi.org/10.3390/ ijerph18073557

Received: 12 March 2021

Accepted: 26 March 2021

Published: 30 March 2021

Publisher's Note: MDPI stays neutral with regard to jurisdictional claims in published maps and institutional affiliations.

Copyright: (c) 2021 by the authors. Licensee MDPI, Basel, Switzerland. This article is an open access article distributed under the terms and conditions of the Creative Commons Attribution (CC BY) license (https:// creativecommons.org/licenses/by/ $4.0 /)$.
The authors wish to correct the following in this paper [1].

The fourth author, Ching-Huang Lai, should be affiliated with:

1 Graduate Institute of Life Sciences, National Defense Medical Center, Taipei 114, Taiwan

3 School of Public Health, National Defense Medical Center, Taipei 114, Taiwan

The authors would like to apologize for any inconvenience caused to the readers by this change.

\section{Reference}

1. Su, T.Y.; Pan, C.H.; Hsu, Y.T.; Lai, C.H. Effects of Heavy Metal Exposure on Shipyard Welders: A Cautionary Note for 8-Hydroxy-2'-Deoxyguanosine. Int. J. Environ. Res. Public Health 2019, 16, 4813. [CrossRef] [PubMed] 